\title{
Aa. Vv., Gaston Paris (1839-1903). Philologue, médiéviste, grammairien
}

\section{Irene Finotti}

\section{(2) OpenEdition}

10 Journals

\section{Édition électronique}

URL : http://journals.openedition.org/studifrancesi/32752

DOI : $10.4000 /$ studifrancesi.32752

ISSN : 2421-5856

Éditeur

Rosenberg \& Sellier

\section{Édition imprimée}

Date de publication : 1 décembre 2005

Pagination : 607-608

ISSN : 0039-2944

\section{Référence électronique}

Irene Finotti, «Aa. Vv., Gaston Paris (1839-1903). Philologue, médiéviste, grammairien », Studi Francesi [En ligne], 147 (XLX | III) | 2005, mis en ligne le 30 novembre 2015, consulté le 19 avril 2021. URL : http:// journals.openedition.org/studifrancesi/32752 ; DOI : https://doi.org/10.4000/studifrancesi.32752

Ce document a été généré automatiquement le 19 avril 2021.

\section{(c) (i) (9)}

Studi Francesi è distribuita con Licenza Creative Commons Attribuzione - Non commerciale - Non opere derivate 4.0 Internazionale. 


\title{
Aa. Vv., Gaston Paris (1839-1903). Philologue, médiéviste, grammairien
}

\author{
Irene Finotti
}

\section{RÉFÉRENCE}

Gaston Paris (1839-1903). Philologue, médiéviste, grammairien, «Revue des langues romanes», CVI, 1 (2002).

1 Ce volume est le résultat d'une journée d'étude consacrée au grand philologue médiéviste et grammairien.

2 Teddy ARNAVIELLE, Sur quelques idées-force de Gaston Paris: fidélité et évolution, pp. 3-16. Bien que Gaston Paris n'ait pas produit une grammaire historique à lui, il a donné un grand apport à la linguistique par des articles, des comptes rendus ou, encore, par sa Leçon d'ouverture du Cours de grammaire historique. En examinant ce texte d'un jeune homme de 29 ans, ainsi que les comptes rendus à deux ouvrages fondamentaux comme la Vie des mots de Darmesteter et l'Histoire de la langue française de Brunot, T.A. met en valeur l'évolution et la fermeté des convictions de Paris dans ce domaine.

3 Gabriel BERGounioux et Jean-Claude CHEVALIER, Gaston Paris et la phonétique, pp. 17-40. Gaston Paris a commencé très tôt ses études de phonéticien en sortant de l'Ecole des Chartes avec un mémoire sur le rôle de l'accent latin dans la langue française (dont G.B. et J.-C.C. soulignent les rapports avec les enseignements de Guessard, de Paulin Paris et de Diez). Deux autres étapes marqueront la suite des travaux de Gaston Paris dans ce domaine: les deux longs comptes rendus sur le Précis de phonétique française de Bourciez et sur la thèse sur la dissimilation consonantique de Maurice Grammont.

4 Charles RIDOux, La carrière et la personnalité scientifique de Gaston Paris, pp. 41-48. D’après C.R. l'admirable et complexe carrière de Gaston Paris doit être envisagée par rapport aux trois grandes personnalités qui l'ont orientée. C'est grâce à son père que l'amour pour sa patrie et le goût pour la littérature du Moyen Age s'enracinent en lui. Pourtant, la méthode pour affronter ces études l'éloigne de Paulin et le rapproche de son 
compagnon, Paul Meyer, avec qui il partage une exigence de sérieux et un strict esprit critique. L'idéal scientifique de Gaston Paris semble enfin correspondre à celui de Pasteur, d'après ce qu'il déclare lui-même dans son discours de réception à l'Académie Française.

Ursula BÄHLER, Gaston Paris et Ferdinand Brunetière: deux mondes, pp. 49-68. Bien qu'ils ne soient, ni l'un ni l'autre, des adeptes du positivisme, le portrait de Gaston Paris correspond en négatif à celui d'un Ferdinand Brunetière, méfiant à l'égard du pouvoir des sciences sur l'orientation morale de la société et convaincu que la science et le respect pour la vérité ne favorisent que l'individualisme. La rupture entre les deux savants prend encore plus de consistance quand on considère l'attitude méprisante de Brunetière vis-à-vis de la littérature médiévale et, par conséquent, de la philologie romane, doctrine auxiliaire au service de la linguistique et de l'histoire.

Alain CORBELLARI, Gaston Paris vu par Joseph Bédier, pp. 69-79. A.C. analyse les relations entre Bédier et Paris qu'il avait déjà tracées dans sa biographie Joseph Bédier écrivain et philologue (1997). Comme il le disait dans ce premier travail, le portrait bédiérien de Paris se compose de six figures: le père, le maitre, le savant, le vulgarisateur, l'humaniste et l'adversaire. Mais ce qui retient davantage l'attention de A.C. dans cette contribution c'est cette dernière catégorie, étant donné l'engagement que Bédier a toujours montré à faire comprendre la beauté des textes médiévaux à ceux qui, comme son maître, ne voulaient pas la voir.

7 Anne-Marguerite FRÝBA-REBER, Gaston Paris et la Suisse, pp. 81-107. Il paraît que les contacts de Gaston Paris avec la Suisse ont eu lieu hors de la Suisse même. Il s'agit de relations de deux genres: celles qu'il a établies grâce à son rôle et à sa réputation d'enseignant estimé dans l'Europe entière et de fondateur de la philologie romane en France (parmi les auditeurs étrangers qui suivaient ses cours, il y en avait beaucoup qui arrivaient de la Suisse pour compléter leur parcours de romanistes); et celles qu'il a entretenues avec deux personnages, Adolf Tobler et Charles Morel, connus à Bonn à dix-sept ans, avec qui il sera lié d'amitié pendant toute sa vie en partageant des expériences et en entreprenant des collaborations.

8 Pierre SWIGGERS, Gaston Paris et les débuts de la philologie romane en Belgique, pp. 109-122. Pour illustrer le rôle de Gaston Paris dans la formation des premiers romanistes belges, P.S. est presque obligé de présenter le parcours du père de la romanistique belge, Maurice Wilmotte. Ses séjours d'étude en France et en Allemagne le persuadent que la Belgique doit garder des liens étroits avec le grand maître - devenu le premier titulaire d'un enseignement de langues et littératures romanes en Belgique, il lui enverra ses meilleurs disciples - qu'il consultera dans une correspondance continue de 1885 à 1902. Jean-François JEANDILLou, Le jugement de Paris: "Un objet d'horreur pour les connaisseurs», pp. 123-135. A partir des années 1920, Gaston Paris prend part au débat sur l'authenticité des Poésies de Marguerite-Eléonore-Clotilde de Vallon-Chalys, depuis Madame de Surville, poète français $d u X V^{e}$ siècle, notamment en rédigeant un compte rendu des ouvrages de deux collègues: en faisant appel tant au langage de la prétendue poétesse qu'aux idées exprimées dans son recueil, Paris proteste fermement contre l'exhortation d'Antonin Macé et Henry Vaschalde, de replacer Clotilde de Surville parmi les grands auteurs de son siècle.

10 Jean DUFOURNET, Gaston Paris et Villon. Entre Auguste Longnon et Marcel Schwob, pp. 137-151. Gaston Paris s'approche de l'étude de Villon par les comptes rendus, à partir de 1867, de l'édition de Pierre Jannet et des différents travaux de Vitu et Longnon. Il peut ainsi 
rendre hommage à ce dernier, qu'il considère un savant rigoureux ayant su ouvrir des voies nouvelles dans la connaissance du poète. Paris avoue encore sa dette envers Longnon dans son ouvrage de synthèse (François Villon, 1901). La deuxième partie de l'article de J.D. est consacrée à l'analyse du «petit livre» de Paris et de ses différences par rapport au Villon de Schwob. 